\title{
The Tracer Diffusivity of Oxygen in Wustite and Cobaltous Oxide
}

\author{
By S. Yamaguchi* and M. Someno* ${ }^{*}$
}

\begin{abstract}
The tracer diffusivity of oxygen in $\mathrm{Fe}_{1-x} \mathrm{O}$ and $\mathrm{CoO}$ has been determined from measurements of the depth profile of ${ }^{18} \mathrm{O}$ by secondary ion mass spectrometry. The tracer diffusivity in $\mathrm{Fe}_{1-x} \mathrm{O}$ was evaluated, by taking into account the surface reaction of oxygen, as $D / \mathrm{m}^{2} \cdot \mathrm{s}^{-1}=(1.17 \pm 0.78) \times$ $10^{-1} \exp [-(375 \pm 23 \mathrm{~kJ} / \mathrm{mol}) / R T]$ between 1093 and $1455 \mathrm{~K}$ for $p_{\mathrm{CO}_{2}} / p_{\mathrm{Co}}=1.00$. The tracer diffusivity in $\mathrm{Fe}_{1-x} \mathrm{O}$ increased with increasing $x$. The surface reaction rate constant was expressed as $K / \mathrm{m} \cdot \mathrm{s}^{-1}=(48.3 \pm 27.5) \exp [-(293 \pm 14 \mathrm{~kJ} / \mathrm{mol}) / R T]$. The tracer diffusivity in CoO was estimated, by taking account of evaporation of $\mathrm{CoO}$, as $D / \mathrm{m}^{2} \cdot \mathrm{s}^{-1}=(8.76 \pm 5.67) \times 10^{-8} \exp [-(287 \pm 18 \mathrm{~kJ} /$ $\mathrm{mol}) / R T]$ between 1273 and $1573 \mathrm{~K}$ for $p_{\mathrm{O}_{2}}=21.3 \mathrm{kPa}(0.21 \mathrm{~atm})$. The evaporation rate was expressed as $V / \mathrm{m} \cdot \mathrm{s}^{-1}=(2.65 \pm 1.59) \times 10^{-5} \exp [-(167 \pm 16 \mathrm{~kJ} / \mathrm{mol}) / R T]$.
\end{abstract}

(Received December 17, 1981)

\section{Introduction}

Wustite $\left(\mathrm{Fe}_{1-x} \mathrm{O}\right)$ has a large deviation from stoichiometry, depending on $p_{\mathrm{O}_{2}}$. No measurements have been reported on the tracer diffusivity of oxygen in $\mathrm{Fe}_{1-x} \mathrm{O}$. The tracer diffusivity in cobaltous oxide $(\mathrm{CoO})$, on the other hand, has been measured near 1 atm $\left(10^{5} \mathrm{~Pa}\right) p_{\mathrm{O}_{2}}$. While the defect structure of $\mathrm{CoO}$ has been well established by thermogravimetry $^{(1)}$ and electrical conductivity measurements $^{(1)(2)}$ in a wide range of oxygen gas pressures, the $p_{\mathrm{O}_{2}}$ dependence of the diffusivities of oxygen in $\mathrm{CoO}$ has not been established.

Mass spectrometric measurement of the gas phase has been commonly used for determining the tracer diffusivity of oxygen at near atmospheric pressures. However, only a few studies at low $p_{\mathrm{O}_{2}}$ have been reported using this method. The oxygen tracer diffusivity in $\mathrm{Fe}_{3} \mathrm{O}_{4}$ has been measured with gas mixture of $\mathrm{H}_{2}-\mathrm{H}_{2} \mathrm{O}^{(3)}$, and other measurements were made by changing the total pressure of pure $\mathrm{O}_{2}$ gas from $10^{-3}$ atm $(0.10 \mathrm{kPa})$ to $1 \mathrm{~atm}(101$ $\mathrm{kPa})^{(4)}$ or by using pure $\mathrm{CO}_{2}$ gas $^{(5)}$. It becomes necessary to establish new techniques to measure the diffusivity of oxygen in oxides at

* Department of Metallurgical Engineering, Tokyo Institute of Technology, Megro-ku, Tokyo 152, Japan.

$\dagger$ Now with Nagaoka University of Technology and Science, Nagaoka, Niigata 949-54, Japan. low $p_{\mathrm{O}_{2}}$, in order to investigate those oxides which exist only under low $p_{\mathrm{O}_{2}}$, such as $\mathrm{Fe}_{1-x} \mathrm{O}$, or over a wide range of oxygen pressures.

In the present work, we have developed a gas sealed capsule method, in which oxide samples are diffusion annealed in a $\mathrm{CO}-\mathrm{CO}_{2}$ gas mixture containing ${ }^{18} \mathrm{O}$ and are analyzed to get the ${ }^{18} \mathrm{O}$ concentration profile by secondary ion mass spectrometry (SIMS). The SIMS technique has previously been succesfully applied to the tracer diffusion of oxygen in rutile $^{(6)}$ and sulfur in calcium sulfide ${ }^{(7)}$.

\section{Experimental Procedure}

\section{Materials}

Materials used in this study were a single crystal boule of cobaltous oxide prepared by the Verneuil method, and sheets of oxidized wustite. The single crystal boule was supplied by Murakami Eng. Co. Ltd. (Yokohama, Japan), and had a purity of at least $99.9 \%$. A qualitative analysis by SIMS showed that the $\mathrm{CoO}$ crystal contained impurities such as $\mathrm{Al}$, $\mathrm{Si}, \mathrm{Ti}$, and $\mathrm{Na}$ and that the relative intensities of secondary ion did not change with diffusion annealing. The CoO boule was either sliced by a diamond cutting wheel or cleaved along (100) plane to give specimens about $5 \mathrm{~mm} \times 5 \mathrm{~mm} \times$ $1 \mathrm{~mm}$ in size. $\mathrm{Fe}_{1-x} \mathrm{O}$ sheets were made from and $\mathrm{Fe}$ rod (Johnson and Mathey Co.), which contained $0.03 \% \mathrm{C}, 0.01 \% \mathrm{O}, 0.01 \% \mathrm{~N}, 3 \mathrm{ppm}$ 
$\mathrm{Mn}, 1 \mathrm{ppm} \mathrm{Cu}$, and residuals $(\mathrm{Mg}, \mathrm{Ag}, \mathrm{Ca})$ less than $1 \mathrm{ppm}$. This rod was cold-rolled and sliced to a sheet about $10 \mathrm{~mm} \times 40 \mathrm{~mm} \times$ $1 \mathrm{~mm}$ in size, and then oxidized in a recrystallized alumina tube under $\mathrm{CO}-\mathrm{CO}_{2}$ mixture. The $\mathrm{Fe}_{1-x} \mathrm{O}$ sheet specimens thus obtained were polycrystalline with grain diameters ranging from 3 to $4 \mathrm{~mm}$.

Oxygen gas and carbon dioxide gas, both containing 20 at $\%{ }^{18} \mathrm{O}$, were supplied from British Oxygen Co. Ltd. (London, England).

$\mathrm{Fe}_{1-x} \mathrm{O}$ and $\mathrm{CoO}$ sheet specimens were polished with abrasive paper (\#280-1200), diamond paste $(3 \mu \mathrm{m})$, and $\mathrm{Al}_{2} \mathrm{O}_{3}$ polishing powder $(0.5 \mu \mathrm{m})$, and were pre-annealed for homogenization either in dried air, dried pure natural $\mathrm{O}_{2}$ gas, or $\mathrm{CO}-\mathrm{CO}_{2}$ gas mixture at the same temperature and the same $\mathrm{CO}_{2} / \mathrm{CO}$ ratio as in the diffusion annealing, but for a longer than the diffusion time. The preannealing time was long enough to attain a homogeneous composition throughout the samples after quenching with $\mathrm{Ar}$ gas. The samples of wustite were then chemically polished in concentrated phosphoric acid to remove the contaminated surface layer.

\section{Experimental procedure of diffusion}

The $\mathrm{CoO}$ diffusion annealing was done in a closed chamber apparatus ${ }^{(6)}$, the $\mathrm{CoO}$ sample covered with a platinum mesh holder being placed in a recrystallized alumina protecting tube within a quartz chamber. After evacuating the closed chamber to $10^{-1} \mathrm{~Pa},{ }^{18} \mathrm{O}_{2}$ gas was introduced into the chamber to $21.3 \mathrm{kPa}$ $(0.21 \mathrm{~atm})$, and then, a pre-heated furnace was moved to cover the chamber. The chamber temperature was monitored by a Pt-13\% Rh-Pt thermocouple, and the oxygen gas pressure was monitored and adjusted from time to time. At the end of the diffusion annealing, the furnace was removed, and the chamber was quenched by pouring water over it. The experimental conditions for the $\mathrm{CoO}$ samples are summarized in Table 1.

The diffusion annealing for all the $\mathrm{Fe}_{1-x} \mathrm{O}$ samples was carried out in gas sealed quartz capsules ${ }^{(7)}$, in which the $\mathrm{Fe}_{1-x} \mathrm{O}$ sheets were enclosed. A washed quartz tube of $26.5 \mathrm{mmID}$ containing four separately placed samples in a platinum mesh holder was evacuated for at least $3.6 \mathrm{ks}(1 \mathrm{~h})$, and a mixture of $\mathrm{C}^{18} \mathrm{O}_{2}$ gas and $\mathrm{C}^{16} \mathrm{O}$ gas were then introduced into the quartz tube. After $1.8 \mathrm{ks}$ (30 min), during which the gas mixture was homogenized, four $100 \mathrm{~mm}$ long capsules were sealed off, each containing one sample and all with the same gas composition. The total pressure in the capsules at room temperature was so determined that it could be $101 \mathrm{kPa}$ (1 atm) at the highest annealing temperature of four samples. The capsules were then placed in an annealing furnace, and at the end of the diffusion annealing, they were quenched in water. The experimental conditions for $\mathrm{Fe}_{1-x} \mathrm{O}$ samples are summarized in Table 2.

\section{Depth profiling method}

The depth profiles of ${ }^{18} \mathrm{O}$ and ${ }^{16} \mathrm{O}$ in the diffusion annealed samples were obtained by measuring the intensity of negative singly charged ions with a Hitachi ion micro-analyzer

Table 1 Conditions for homogenization and diffusion annealing and determined diffusivities of $\mathrm{CoO}$.

\begin{tabular}{rcccccc}
\hline \hline $\begin{array}{c}\text { Sample } \\
\text { No. }\end{array}$ & Temp. & $\begin{array}{c}\text { Pre-ann. } \\
\text { time }\end{array}$ & $p_{\mathbf{O}_{2}}$ & $\begin{array}{c}\text { Diff-ann. } \\
\text { time }\end{array}$ & $\begin{array}{c}\text { Tracer } \\
\text { diffusivity }\end{array}$ & $\begin{array}{c}\text { Evaporation } \\
\text { rate }\end{array}$ \\
\hline & $\mathrm{K}$ & $10^{4} \mathrm{~s}$ & $\mathrm{~Pa}$ & $10^{4} \mathrm{~s}$ & $\mathrm{~m}^{2} / \mathrm{s}$ & $\mathrm{m} / \mathrm{s}$ \\
\hline $1-1$ & 1323 & 9.36 & 81.1 & 8.64 & $4.51 \times 10^{-19}$ & $3.64 \times 10^{-10}$ \\
5 & 1473 & 43.3 & 21.3 & 8.22 & $5.35 \times 10^{-18}$ & $3.04 \times 10^{-11}$ \\
6 & 1573 & 37.8 & 21.3 & 3.51 & $2.94 \times 10^{-17}$ & $1.07 \times 10^{-10}$ \\
11 & 1273 & 92.5 & 21.3 & 14.0 & $2.20 \times 10^{-19}$ & $4.91 \times 10^{-10}$ \\
20 & 1516 & 12.6 & 21.3 & 1.90 & $1.32 \times 10^{-17}$ & $4.42 \times 10^{-11}$ \\
23 & 1408 & 7.73 & 21.3 & 8.65 & $2.30 \times 10^{-18}$ & $1.80 \times 10^{-11}$ \\
24 & 1298 & 7.95 & 21.3 & 4.22 & $1.67 \times 10^{-19}$ & $5.15 \times 10^{-12}$ \\
30 & 1408 & 10.5 & 21.3 & 4.33 & $1.66 \times 10^{-18}$ & $1.15 \times 10^{-11}$ \\
\hline \hline
\end{tabular}




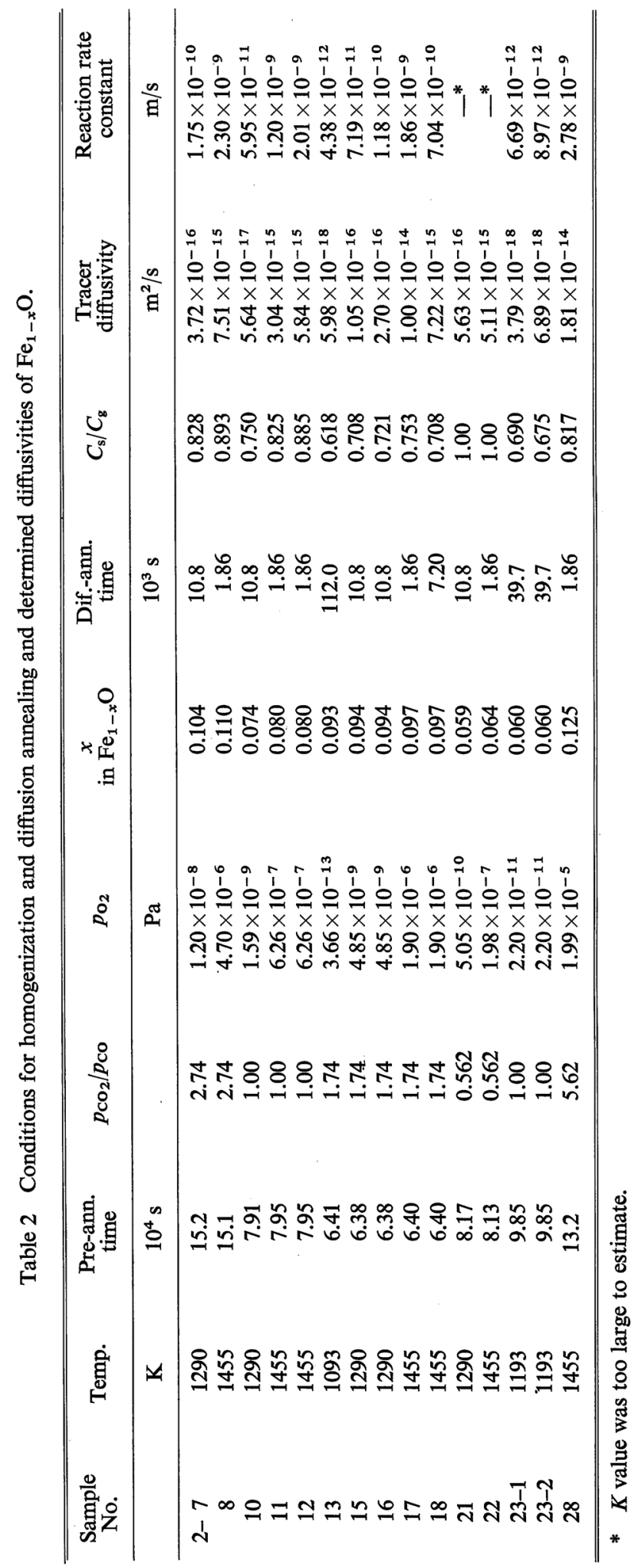


(IMA).

The conditions of the IMA were in general the same as those in a previous report ${ }^{(6)}$. After each analysis, the diameter and the depth of the ion etched crater were measured with a surface profilometer. Flat bottomed craters were obtained, typical crater profiles for $\mathrm{Fe}_{1-x}$ $\mathrm{O}$ and $\mathrm{CoO}$ being shown in Fig. 1.

\section{Results}

Typical measurements of the depth profile of the oxygen isotopes in $\mathrm{CoO}$ and $\mathrm{Fe}_{1-x} \mathrm{O}$ are shown in Figs. 2 and 3, respectively. $C_{\mathrm{g}}$ and $C_{0}$ are the initial concentration of ${ }^{18} \mathrm{O}$ in the gas phase and in the solid phase, respectively, and $C$ is the concentration of ${ }^{18} \mathrm{O}$ in the solid at depth $x$, and $C_{\mathrm{s}}$ is the concentration of ${ }^{18} \mathrm{O}$ at surface of the solid phase $(x=0)$. The initial concentration $\left(C_{0}\right)$ is considered to be the sum of the concentration of naturally occurring ${ }^{18} \mathrm{O}$ and the background in the IMA analysis. In this study, the ${ }^{18} \mathrm{O}$ concentration in a region far from the diffusion penetration was very close to the natural ${ }^{18} \mathrm{O}$ concentra-

\section{(a) $\mathrm{CoO}$ sample No.1-30}

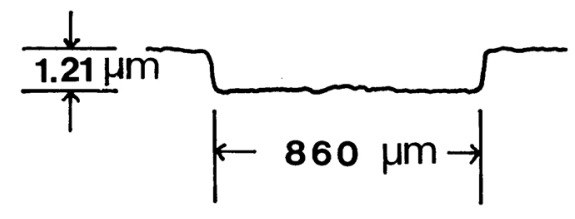

\section{(b) $\mathrm{F}^{\prime} \mathrm{e}_{1-\mathrm{x}} \mathrm{O}$ sample No. 2-17}

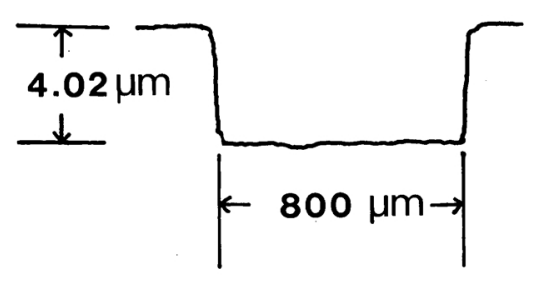

Fig. 1 Profilometric measurements of sputtered craters.

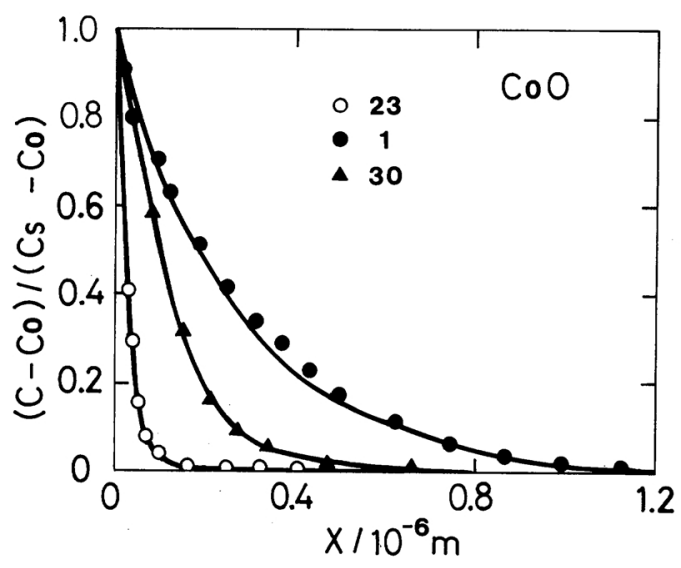

Fig. 2 Measured concentration profiles of ${ }^{18} \mathrm{O}$ in CoO. Solid line shows the theoretical curve of eq. (A-4) from calculated $D$ and $V$.

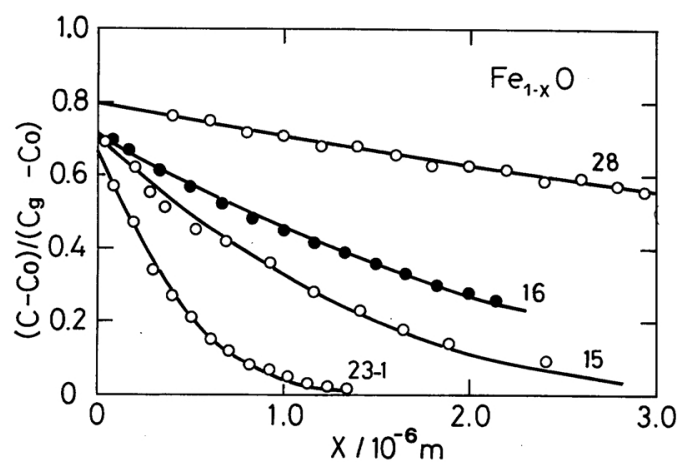

Fig. 3 Measured concentration profiles of ${ }^{18} \mathrm{O}$ in $\mathrm{Fe}_{1-x} \mathrm{O}$. Solid line shows the theoretical curve of eq. (A-3) from calculated $D$ and $K$.

tion $(0.204$ at $\%)$.

The distance from the surface in Figs. 2 and 3 was calculated from the sputter time and the sputter rate, the latter being determined from profilometer measurements of the crater depth.

In the case of $\mathrm{CoO}$, evaporation from the surface could not be ignored, for deposition of $\mathrm{CoO}$ on the $\mathrm{Al}_{2} \mathrm{O}_{3}$ protecting tube were clearly observed after each diffusion annealing, and in addition, the inverse error function plot of $\left(C-C_{0}\right) /\left(C_{\mathrm{s}}-C_{0}\right)$ along with eq. (A-1) was not linear but convex upward. The diffusivities were, therefore, calculated by eq. (A-4), in which the evaporation effect was taken into account.

The values of $D$ calculated from eq. (A-4) are plotted against the reciprocal temperature 


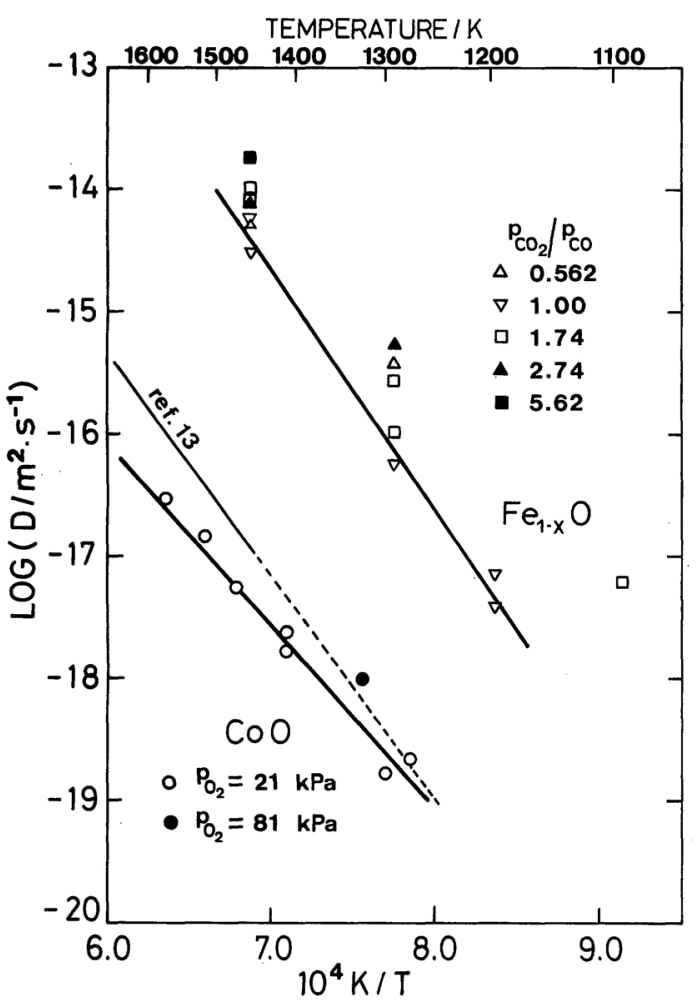

Fig. 4 Arrhenius plot of tracer diffusivities of oxygen in single crystalline $\mathrm{CoO}$ and polycrystalline $\mathrm{Fe}_{1-x} \mathrm{O}$.

in Fig. 4. The equation of best fit for the measured $D$ values for $p_{\mathrm{O}_{2}}=21 \mathrm{kPa}(0.21 \mathrm{~atm})$ can be expressed as

$$
\begin{aligned}
D / \mathrm{m}^{2} \cdot \mathrm{s}^{-1}= & (8.76 \pm 5.67) \times 10^{-8} \\
& \times \exp [-(287 \pm 18 \mathrm{~kJ} / \mathrm{mol}) / R T],
\end{aligned}
$$

where $R$ is the gas constant $\left(8.314 \mathrm{~J} \cdot \mathrm{mol}^{-1}\right.$. $\mathrm{K}^{-1}$ ) and $T$ is the temperature in $\mathrm{K}$. The $D$ values are listed in Table 1 . The surface evaporation rate constant was simultaneously obtained, and listed in Table 1. The $V$ values are plotted against the reciprocal temperature in Fig. 5, and can be expressed as

$$
\begin{aligned}
V / \mathrm{m} \cdot \mathrm{s}^{-1}= & (2.65 \pm 1.59) \times 10^{-5} \\
& \times \exp [-(167 \pm 16 \mathrm{~kJ} / \mathrm{mol}) / R T] .
\end{aligned}
$$

For $\mathrm{Fe}_{1-x} \mathrm{O}$, the surface ${ }^{18} \mathrm{O}$ composition was different from that of the gas phase. This indicates that ${ }^{18} \mathrm{O}$ transfer from the gas phase to the solid phase was controlled not only by diffusion in the solid but also by an oxygen surface exchange reaction.

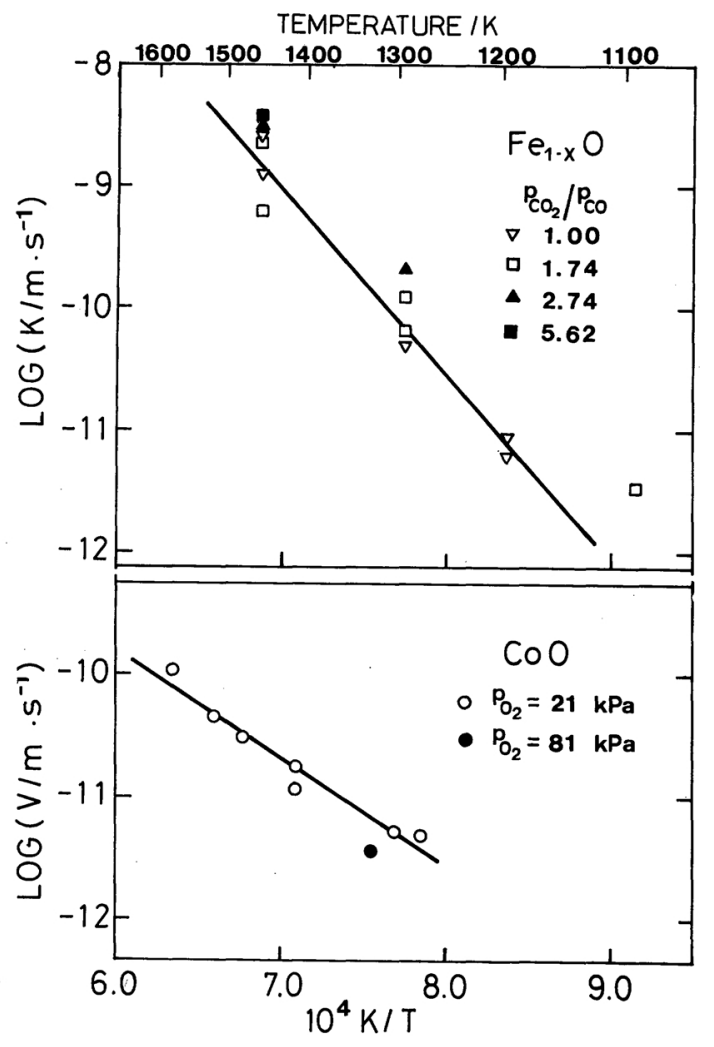

Fig. 5 Arrhenius plot of surface reaction rate constants $K$ for $\mathrm{Fe}_{1-x} \mathrm{O}$ and evaporation rate constants $V$ for $\mathrm{CoO}$.

The values of $D$ and $K$ for $\mathrm{Fe}_{1-x} \mathrm{O}$ were determined from eq. (A-3) by the least squares method, and are listed in Table 2. The calculated values of $D$ and $K$ are plotted against the reciprocal temperature in Figs. 4 and 5 , respectively. The equation of best fit for the measured $D$ values for $\mathrm{Fe}_{1-x} \mathrm{O}$ and $p_{\mathrm{CO}_{2}} / p_{\mathrm{CO}}=$ 1.00 can be expressed as

$$
\begin{aligned}
D / \mathrm{m}^{2} \cdot \mathrm{s}^{-1}= & (1.17 \pm 0.78) \times 10^{-1} \\
& \times \exp [-(375 \pm 23 \mathrm{~kJ} / \mathrm{mol}) / R T] .
\end{aligned}
$$

The surface reaction constant can be expressed as

$$
\begin{aligned}
K / \mathrm{m} \cdot \mathrm{s}^{-1}= & (48.7 \pm 27.5) \\
& \times \exp [-(293 \pm 14 \mathrm{~kJ} / \mathrm{mol}) / R T] .
\end{aligned}
$$

In Fig. 6 , the $D$ values at $1455 \mathrm{~K}$ are plotted against the composition $x$ in $\mathrm{Fe}_{1-x} \mathrm{O}$. The values of $x$ were estimated from the $\mathrm{CO}_{2} / \mathrm{CO}$ ratio $^{(8)-(10)}$ at this temperature.

For $\mathrm{CoO}$ samples diffusion-annealed by the 


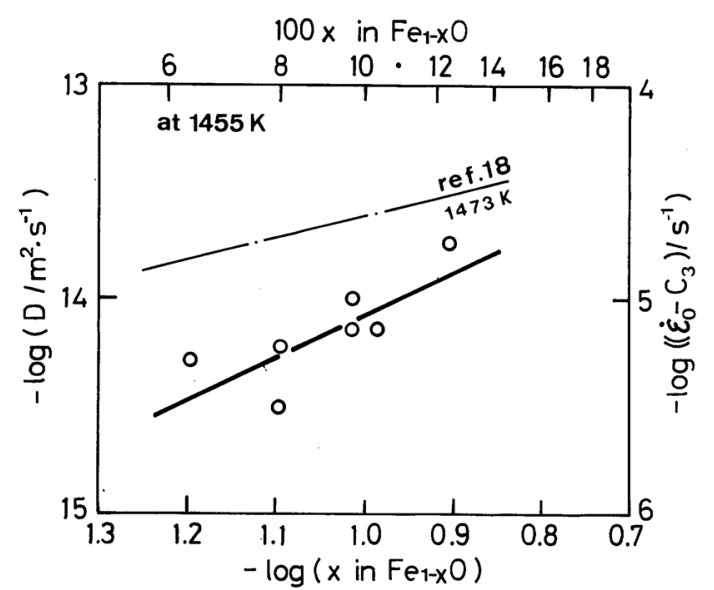

Fig. 6 Dependence of tracer diffusivity of oxygen on composition $x$ in $\mathrm{Fe}_{1-x} \mathrm{O}$.

sealed capsule method in a $\mathrm{C}^{18} \mathrm{O}-\mathrm{C}^{16} \mathrm{O}$ gas mixture with a $\mathrm{CO}_{2} / \mathrm{CO}$ ratio ranging from 10 to 50 , the $\mathrm{Ar}^{+}$ion-bombarded surface was positively charged. The buit-up charge was eliminated by the electron spray $\operatorname{method}^{(7)}$, but the intensity of the positive ions, including ${ }^{18} \mathrm{O}$ and ${ }^{16} \mathrm{O}$, was too small and the errors too great to calculate the $D$ value.

\section{Discussion}

For some CoO samples, the surface concentration of ${ }^{18} \mathrm{O}$ was slightly smaller than the initial concentration of the gas, indicating that the gas composition changed to a similar degree. For the $D$ calculation using eq. (A-4), however, the surface composition $\left(C_{\mathrm{s}}\right)$ was assumed to be unchanged. This assumption caused a small relative error in the calculated $D$ value, i.e. $10 \%$, in comparison with the further assumption that $C_{\mathrm{s}}$ be $0.848 C_{\mathrm{g}}$, based on the minimum value of $C_{\mathrm{s}}$.

Regarding oxygen tracer diffusivities in $\mathrm{CoO}$, three studies have been reported. One is a measurement at $p_{\mathrm{O}_{2}}=0.13 \mathrm{~atm}(13 \mathrm{kPa})$ at $1273 \mathrm{~K}$ by Thompson ${ }^{(11)}$, using the mass spectrometric analysis of the gas phase. His data are $10^{5}$ times larger than the present one. Another is a report of $\mathrm{Holt}^{(12)}$, who used the proton activation technique at $p_{\mathrm{O}_{2}}=0.17$ atm $(17 \mathrm{kPa})$ at $1673 \mathrm{~K}$, giving a slightly larger value than the present data. The third report is by Chen and
Jackson $^{(13)}$, who measured the change in the gas phase composition due to the uptake of ${ }^{18} \mathrm{O}$ into the $\mathrm{CoO}$ at $p_{\mathrm{O}_{2}}=0.21 \mathrm{~atm}(21 \mathrm{kPa})$ between 1448 and $1833 \mathrm{~K}$. Their data, shown in Fig. 4, are greater by nearly one order of magnitude than the present data. This large discrepancy is considered to be due to the evaporation having been ignored in Chen and Jackson's report. The apparent amount of ${ }^{18} \mathrm{O}$ takeup in their mass spectrometric method is considered to include the amount taken up by evaporated $\mathrm{CoO}$ as well as that which diffused into solid $\mathrm{CoO}$ sample. Taking this evaporation effect into account, their $D$ values become smaller and closer to the present values.

The calculated evaporation rate constants of $\mathrm{CoO}$ in this work were rather fast, ranging from $4.0 \times 10^{-12}$ to $3.0 \times 10^{-11} \mathrm{~m} / \mathrm{s}$, compared with the value of $\mathrm{NiO}$ due to Dubois ${ }^{(14)}$, about $10^{-14}(\mathrm{~m} / \mathrm{s})$ at $1600 \mathrm{~K}$. The apparent activation energy for evaporation of $\mathrm{CoO}$ in the present study was calculated to be $167 \mathrm{~kJ} / \mathrm{mol}$, which was small compared with the reported value of the activation energy of evaporation, $440 \mathrm{~kJ} /$ $\mathrm{mol}^{(15)}$. This result indicates that the present evaporation condition was intermediate between free evaporation in a small chamber and equilibrium evaporation.

The $D$ value of sample No. $1-1$ for $p_{\mathrm{O}_{2}}=81$ $\mathrm{kPa}(0.80 \mathrm{~atm})$ is apparently higher than that expected from the best fit equation for $p_{\mathrm{O}_{2}}=$ $21 \mathrm{kPa}(0.21 \mathrm{~atm})$ shown in Fig. 4. This result is in good agreement with Seltzer et al's report $^{(16)}$ that the steady state creep rate increases with increasing $p_{\mathrm{O}_{2}}$. A similar dependence of the oxygen diffusivity has been reported for $\mathrm{NiO}$ by $\mathrm{O}$ 'Keefe and Moore ${ }^{(17)}$.

The measurements for $\mathrm{Fe}_{1-x} \mathrm{O}$ show larger scatter than those for $\mathrm{CoO}$. Two reasons for this are possible. One is the anisotropy effect of the crystal structure on diffusion and sputtering. The crystal orientation of the diffusion direction varied from one sample to another, since the $\mathrm{Fe}_{1-x} \mathrm{O}$ samples were polycrystalline and generally only one grain was analyzed in the IMA analysis. The anisotropy in diffusion is caused by the difference in the diffusion direction, but the error due to this effect would be small compared with that due to sputtering. The most probable source of error is considered 
to be the anisotropy in sputtering. Two grains were simultaneously analyzed for sample Nos. 2-8, 12, 15, and 22, and the difference in the sputtering rate between the two grains caused a difference in the crater depth as large as $1.2 \mu \mathrm{m}$. The average of the two depths was used, giving rise to an error $( \pm 20 \%)$ in the evaluation of the diffusivity. The second possible reason, in the case of the polycrystalline $\mathrm{Fe}_{1-x} \mathrm{O}$ samples, is enhanced diffusion along the grain boundaries, though, in this study, only one grain boundary was contained in the sputtered area and the area altered by grain boundary diffusion was negligibly small compared with the sputtered area (1 mm diam.).

There has been as yet no study of oxygen diffusion in $\mathrm{Fe}_{1-x} \mathrm{O}$. Ilschner, Reppich, and Riecke $^{(18)}$ measured the steady state creep rate by a compression technique from 1273 to $1573 \mathrm{~K}$. Their conclusion was that the mechanism of high temperature creep is the flow of oxygen vacancies between dislocations. Their results are in excellent agreement with the present ones in their activation energy being $326 \mathrm{~kJ} / \mathrm{mol}$ for creep under constant composition $x$ and the present value being $375 \mathrm{~kJ} / \mathrm{mol}$ for the tracer diffusion of oxygen under a constant $\mathrm{CO}_{2} / \mathrm{CO}$ ratio of 1.00 .

The composition dependence of $D$ in $\mathrm{Fe}_{1-x} \mathrm{O}$ shown in Fig. 6 is expressed as

$$
\log \left(D / \mathrm{m}^{2} \cdot \mathrm{s}^{-1}\right)=1.92 \log x-12.1 .
$$

The slope for the steady state creep rate, due to Ilschner et al., is compared with the present results in Fig. 6. Both the "diffusion" and the "creep" slopes are very close, indicating that the creep rate is determined by diffusion of oxygen. In view of the $p_{\mathrm{O}_{2}}$ or the composition dependence of $D$ shown in Fig. 6, the simple vacancy mechanism can not be considered to operate on diffusion of oxygen in $\mathrm{Fe}_{1-x} \mathrm{O}$. This is because, if so, the diffusivity should decrease with increasing $x$ or $p_{\mathrm{O}_{2}}$.

The most plausible mechanism in $\mathrm{Fe}_{1-x} \mathrm{O}$, therefore, seem to be the interstitialcy diffusion via cation vacancy proposed by Howng and Wagner, $\mathrm{Jr}^{\left({ }^{(19)}\right.}$ for the diffusion of sulfur in NiO. This model may be simply expressed as $^{(20)}$

$$
D=a_{0} \gamma N_{\mathrm{V}}^{\mathrm{Fe}} N_{\mathrm{I}}^{\mathrm{o}},
$$

where $a_{0}$ is the jump distance, $\gamma$ is a geometrical factor, $N_{\mathrm{v}}^{\mathrm{Fe}}(=2 x)$ is the number of Fe vacancies, and $N_{\mathrm{I}}^{\mathrm{O}}$ is the number of oxygen atoms diffusing via octahedral iron vacancies. Since $N_{\mathrm{I}}^{\mathrm{O}}$ is considered to depend linearly on the number of $\mathrm{Fe}$ vacancies, the last equation is related to $x$ as $D \propto x^{2}$, or $\log D \propto 2 \log x$. This relation is in good agreement with the present data in Fig. 6.

The activation enthalpy for diffusion in $\mathrm{CoO}$ and $\mathrm{Fe}_{1-x} \mathrm{O}$ in the present study has been compared with other oxygen diffusivities in oxides with $\mathrm{NaCl}$ type structure. The enthalpy for $\mathrm{MgO}$ was reported to be $261^{(23)}$ and $344^{(24)}$ $\mathrm{kJ} / \mathrm{mol}$, and for $\mathrm{CoO} 397 \mathrm{~kJ} / \mathrm{mol}^{(13)}$. The value for $\mathrm{NiO}$ was reported as $241^{(17)}$ and $538^{(14)} \mathrm{kJ} / \mathrm{mol}$. The present values for $\mathrm{CoO}$ and $\mathrm{Fe}_{1-x} \mathrm{O}$ were 287 and $375 \mathrm{~kJ} / \mathrm{mol}$ (for $\left.p_{\mathrm{CO}_{2}} / p_{\mathrm{CO}}=1.00\right)$, respectively, and are in intermediate between the other values.

\section{Summary}

The tracer diffusivity of oxygen in $\mathrm{Fe}_{1-x} \mathrm{O}$ and $\mathrm{CoO}$ was estimated by the SIMS method. For $\mathrm{Fe}_{1-x} \mathrm{O}$, the diffusivity was calculated by taking into account the surface exchange reaction. The diffusivity was increased with increasing deviation from stoichiometry, $x$, and the mechanism for oxygen diffusion was suggested as an interstitialcy mechanism. The diffusivity of oxygen in $\mathrm{CoO}$ was calculated by taking into account the evaporation of $\mathrm{CoO}$ from surface, and was compared with reported values.

\section{Acknowledgements}

The authors wish to thank Prof. K. S. Goto of Tokyo Institute of Technology for his interest and for valuable suggestion. We are grateful to Dr. M. Arita and Dr. M. Kobayashi for helpful advice and discussion.

\section{REFERENCES}

(1) N. G. Eror and J. B. Wagner, Jr.: J. Phys. Chem. Solids, 29 (1968), 1597.

(2) B. Fisher and D. S. Tannhauser: J. Chem. Phys., 44 (1966), 1663.

(3) J. E. Castle and P. L. Surman: J. Phys. Chem., 71 (1967), 4255; 73 (1969), 632.

(4) W. K. Chen and R. A. Jackson: J. Chem. Phys., 
47 (1967), 1144.

(5) K. Ando and Y. Oishi: Extended Abstracts of Third International Meeting on Solid Electrolytes, September, 1980, Japan, p. 26.

(6) M. Arita, M. Hosoya, M. Kobayashi and M. Someno: J. Am. Cer. Soc., 62 (1979), 443.

(7) T. Otowa, M. Kobayashi, K. S. Goto and M. Someno: J. Japan Inst. Metals, 43 (1979), 1181 (in Japanese).

(8) L. S. Darken and R. W. Gurry: J. Am. Chem. Soc., 67 (1945), 1398; 68 (1946), 1318.

(9) I. Bransky and A. Z. Hed: J. Am. Cer. Soc., 57 (1968), 232.

(10) P. Kofstad and A. Z. Hed: J. Electrochem. Soc., 115 (1968), 102.

(11) B. A. Thompson: in P. Kofstad, Nonstoichiometry, Diffusion, and Electrical Conductivity in Binary Metal Oxides, Wiley, N.Y., (1972), p. 244.

(12) J. B. Holt: ibid., p. 244.

(13) W. K. Chen and R. A. Jackson: J. Phys. Chem. Solids, 30 (1969), 1309.

(14) C. Dubois: Ph.D. thesis, University of Paris, 1979.

(15) M. S. Chandrasekhaiah: Vapor Pressure of Elements, J. L. Margrave Ed., The Characterization of High-Temperature Vapors, John-Wiley \& Sons, 1967.

(16) A. H. Clauer, M. S. Seltzer and B. A. Wilcox: J. Mat. Sci., 6 (1971), 1379.

(17) M. O'Keeffe and W. J. Moore: J. Phys. Chem., 65 (1961), 1438.

(18) B. Ilschner, B. Reppich and E. Riecke: Disc. faraday Soc., No. 38 Dislocation in Solid, (1964).

(19) W. Y. Howng and J. B. Wagner, Jr.: J. Phys. Chem. Solids, 39 (1978), 1019.

(20) P. G. Shewmon: Diffusion in Solids, McGrawHill, N.Y., (1963), p. 151.

(21) J. Crank: Mathematics of Diffusion, 2nd Ed., Oxford Univ. Press, London, (1975), p. 35.

(22) D. Shaw: Atomic Diffusion in Semiconductors, D. Shaw Ed., Plenum Press, london (1973), p. 58.

(23) Y. Oishi and W. D: Kingery: J. Chem. Phys., 33 (1960), 905.

(24) L. H. Rovner: in P. Kofstad, Nonstoichiometry, Diffusion, and Electrical Conductivity in Binary Metal Oxides, Wiley, N.Y., (1972), p. 121.

\section{Appendix}

The solution of Fick's second law for semiinfinite media under constant surface concentration is solved as ${ }^{(20)}$

$$
\left(C-C_{0}\right) /\left(C_{\mathrm{s}}-C_{0}\right)=\operatorname{erfc}(x / 2 \sqrt{D t}),
$$

where $C$ is the isotope concentration at time $t$ and depth $x, C_{\mathrm{s}}$ is the concentration at the surface, $C_{0}$ is the initial concentration in solid, and $D$ is the diffusivity.

When $C_{\mathrm{s}}$ varies with time due to surface exchange reaction, if the reaction is assumed to be of the first order, the boundary condition for diffusion at the solid surface is

$$
-D(d C / d r)_{\mathrm{at} r=0}=K\left(C_{0}-C_{\mathrm{s}}\right),
$$

where $K$ is the rate constant of the exchange reaction. The solution of Fick's second law for this boundary condition is ${ }^{(21)}$

$$
\begin{aligned}
\left(C-C_{0}\right) /\left(C_{\mathrm{g}}-C_{0}\right)= & \operatorname{erfc}(x / 2 \sqrt{D t}) \\
& -\exp \left(h x+h^{2} D t\right) \\
& \times \operatorname{erfc}(x / 2 \sqrt{D t}+h \sqrt{D t}),
\end{aligned}
$$

where $C_{\mathrm{g}}$ is the ${ }^{18} \mathrm{O}$ concentration in the gas phase and $h=K / D$. This equation was used for the calculation of $D$ in $\mathrm{Fe}_{1-x} \mathrm{O}$.

When the evaporation is of significance, eq. $(\mathrm{A}-1)$ can be modified to be $\mathrm{e}^{(22)}$

$$
\begin{aligned}
& \left(C-C_{0}\right) /\left(C_{\mathrm{s}}-C_{0}\right)=1 / 2 \\
& =\left[\operatorname{erfc}\left(\frac{x+V t}{2 \sqrt{D t}}\right)+\exp \left(-\frac{V x}{D}\right) \operatorname{erfc}\left(\frac{x-V t}{2 \sqrt{D t}}\right)\right],
\end{aligned}
$$

where $V$ is the evaporation rate constant $(\mathrm{m} / \mathrm{s})$. This equation was used to obtain the $D$ values in $\mathrm{CoO}$. 